\title{
Formación de profesionales en un mundo que necesita alimentos: una mirada amplia
}

\section{Training professionals in a world that needs food: a broad view}

Para realizar un análisis de la formación de profesionales que se vinculan con la alimentación de la humanidad debemos llevarlo a cabo desde una mirada amplia teniendo presente la cultura como un conjunto de modos de vida y costumbres, conocimientos y grado de desarrollo científico, industrial en una época y en un contexto social, en un tiempo y lugar determinado.

De esta manera debemos abordar la formación de estudiantes que hoy empiezan una carrera universitaria ya que serán futuros profesionales, fermentos activos de la sociedad del mañana que estarán tomando decisiones, generando políticas, conduciendo instituciones, educando nuevas generaciones, cambiando la cultura dentro de quince, veinte o veinticinco años, por lo que es nuestra responsabilidad analizar los signos de estos tiempos para proyectar las necesidades y demandas futuras. Los alumnos que hoy se están formando serán los que deban atender a las necesidades del mañana, y hacia allí debemos mirar.

En estos tiempos de pandemia por COVID 19 debería resonar en nuestros pensamientos la encíclica “Laudato Si” que está cumpliendo cinco años, en ella se hace fuerte el mensaje sobre el cuidado de la casa común. Deberíamos identificar escenarios futuros porque no hay un solo camino de solución. Las personas estamos vinculadas hacia nuestro entorno cercano, pero también lo estamos hacia entornos alejados por mas que no lo percibamos. De manera cotidiana nos vinculamos hacia estos ambientes por el simple hecho de comer o de beber un vaso de agua. Esta distancia entre los espacios urbanos y los contextos en los que se producen los alimentos que consumimos pueden generar distorsiones por falta de conocimientos, demandas y necesidades de los diferentes ámbitos.

En referencia al tema de la alimentación, en octubre de 2009 la Organización de las Naciones Unidas para la Agricultura y la Alimentación (Food and Agriculture Organization of the United Nations) realiza una conferencia sobre «Cómo alimentar a la humanidad en 2050 y concluyó que para ese año habría en el mundo una población aproximada de 9.200 millones de personas, que su distribución sería mayormente urbana y con una renta per cápita significativamente mayor, y que para alimentar a una

Revista Methodo: Investigación Aplicada a las Ciencias Biológicas. Facultad de Medicina. Universidad Católica de Córdoba. Jacinto Ríos 571 Bo Gral. Paz. X5004FXS. Córdoba. Argentina. Tel.: (54) 3514517299 / Correo: methodo@ucc.edu.ar / Web: methodo.ucc.edu.ar | EDITORIAL Rev. Methodo 2020;5(3):78-80. 
población más numerosa, más urbana y con mayor poder adquisitivo, era necesario aumentar la producción mundial de alimentos un $70 \%$, la segunda conclusión es que ese aumento debería basarse más en el aumento de la productividad agrícola (80\%) que en la expansión de la superficie cultivada $(20 \%)$.

En el año 2015 la Asamblea General de las Naciones Unidas desarrolló una agenda de trabajo hacia 2030 que abarca una serie de objetivos denominados Objetivos de Desarrollo Sostenible (ODS) y el número dos (2) consiste en erradicar el hambre en el mundo. Resulta difícil entender una sociedad que ha vencido por ejemplo tantas barreras en cuestiones de comunicación en estos últimos tiempos y que no pueda disminuir de manera drástica el número de personas que tiene problemas nutricionales, gente que muere de hambre, siendo una causa importante de esta situación las consecuencias ocasionadas por las guerras, el cambio climático y la distribución de la riqueza.

También es necesario comprender que la problemática de los alimentos se vincula no tan solo a la producción sino también a la disponibilidad tanto física como económica, disponibilidad que implica procesamiento y distribución, pero por sobre todas las cuestiones la problemática de la producción de alimentos se vincula directamente con el consumo, y este se relaciona a la dieta y a la cultura de la población. Se observa que mientras un porcentaje de la población sufre desnutrición o falta total de alimentos hasta provocarle la muerte, existe otro porcentaje con inconvenientes de salud por dietas hipercalóricas o desbalanceadas en su composición por lo que el tema de la producción de alimentos se vincula directamente con el de la nutrición. Tenemos que repensar lo que consumimos y cómo lo producimos. El sistema agroalimentario (producción + industria) ofrece a la sociedad productos que uno tendría dificultad en caracterizarlos como alimento, y esto trae sus consecuencias para la salud pública.

Entonces también debemos formar profesionales que tengan la capacidad de intervenir de manera activa en la producción, industrialización y consumo de alimentos por su potencial de optimizar la salud, mejorar el bienestar, reducir el desarrollo de enfermedades teniendo en cuenta un uso eficiente de los recursos naturales con prácticas agrícolas sustentables enmarcadas en sistemas agroalimentarios sostenibles.

Profesionales que analicen una conexión necesaria entre producción de alimentos transformación - salud de la población todo en una aproximación interdisciplinar de ecología integral (donde todo está conectado) que incorpora la ecología ambiental, económica, social, cultural y la ecología de la vida cotidiana todas como quedan expresadas el capítulo 4 de la encíclica Laudato Si.

Profesionales que sean capaces de trabajar en equipos interdisciplinares, preparados para buscar soluciones integrales y que afronten los desafíos de la alimentación con una mirada tanto en las cuestiones sociales como en las ambientales.

El desafío está llamando a la puerta de nuestra casa común y está aguardando nuestra respuesta....

Revista Methodo: Investigación Aplicada a las Ciencias Biológicas. Facultad de Medicina. Universidad Católica de Córdoba. Jacinto Ríos 571 Bo Gral. Paz. X5004FXS. Córdoba. Argentina. Tel.: (54) 3514517299 / Correo: methodo@ucc.edu.ar / Web: methodo.ucc.edu.ar | EDITORIAL Rev. Methodo 2020;5(3):78-80. 


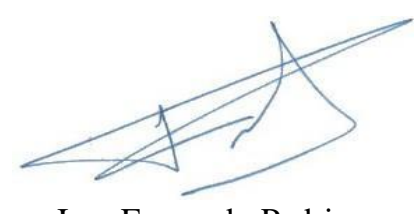

Ing. Fernando Pedri

Decano Facultad Ciencias Agropecuarias

\section{Referencias}

- S.S. Francisco. Carta encíclica LAUDATO SI sobre el cuidado de la casa común. 24 Mayo 2015

- Economistas sin Fronteras. El futuro de la alimentación en el mundo. Dossieres EsF N 33. 2019

-Secretariado para la Justicia Social y la Ecología. Promotio Iustitiae. La Promoción de la Justicia en las Universidades de la Compañía. $\mathrm{N}^{\circ} 1162014 / 3$

- FAO. La FAO en acción 2009 - 2010 en http://www.fao.org/3/am023s/am023s00.pdf

- ONU. Informe de los Objetivos de Desarrollo sostenible 2019 (ODS). En https://www.onu.org.ar/stuff/Informe-ODS-2019.pdf.

\section{(c) (1) (8) \\ BY NC SA}

Revista Methodo: Investigación Aplicada a las Ciencias Biológicas. Facultad de Medicina. Universidad Católica de Córdoba. Jacinto Ríos 571 Bo Gral. Paz. X5004FXS. Córdoba. Argentina. Tel.: (54) 3514517299 / Correo: methodo@ucc.edu.ar / Web: methodo.ucc.edu.ar | EDITORIAL Rev. Methodo 2020;5(3):78-80. 